\title{
Un fantasma recorre los Andes colombianos: socialismo y comunismo en el siglo XIX
}

\author{
Miguel Ángel Urrego \\ Universidad Michoacana de San Nicolás de Hidalgo \\ mangelurrego@gmail.com
}

Title: A Ghost walks the Colombian Andes: socialism and communism in the XIX century

Resumen: A mediados del siglo XIX en Colombia circularon los conceptos de socialismo y comunismo. Esto fue posible debido a la existencia de un lenguaje político radicalizado por el proceso de Independencia; a que los campesinos, negros e indígenas participaron activamente en politica desde el estallido del Movimiento de los Comuneros en 1781; a la organización de los artesanos en las Sociedades Democráticas; a la toma del poder por sectores reformistas del ejército y de los artesanos en 1854; y al permanente contacto con la literatura del primer socialismo europeo. Los conceptos fueron empleados por los artesanos y el sector radical del liberalismo para defender proyectos de reforma social y por ello fueron condenados por el conservatismo y la Iglesia.

Palabras clave: socialismo - comunismo - Colombia - artesanos - Sociedades Democráticas - guerra civil de 1854

\begin{abstract}
In the middle of the 19th century in Colombia, the concepts of socialism and communism circulated. This was possible due to the existence of a political language radicalized by the process of Independence; that peasants, blacks and indigenous people participated actively in politics since the outbreak of the Comuneros Movement in 1781; to the organization of artisans in the Democratic Societies; to the seizure of power by reformist sectors of the army and artisans in 1854; and to the permanent contact with the literature of the first European socialism. The concepts were used by the craftsmen and the radical sector of liberalism to defend projects of social reform and for that reason they were condemned by the conservatism and the Church.
\end{abstract}

Keywords: socialism - communism - Colombia - artisans - Democratic Societies - civil war of 1854

Recepción: 13 de noviembre de 2018. Aprobación: 11 de febrero de 2019

(Archivos, año VII, no 14 , marzo de 2019, pp. 33-52) 


\section{Introducción}

La historia del comunismo y el socialismo en Colombia ha sido tradicionalmente presentada como un suceso propio del siglo XX. ${ }^{1} \mathrm{Y}$ cuando los historiadores aceptan la circulación de estos conceptos en el siglo XIX la perciben como resultado de una moda intelectual de los "señoritos blancos" de las ciudades -que los difundieron entre los sectores artesanales con la intención de movilizarlos de acuerdo a sus intereses- que, por tanto, no corresponde a la realidad colombiana ni a las posibilidades intelectuales o politicas de los sectores populares. Esta postura se hace manifiesta igualmente a la hora de analizar sucesos como las actividades de las Sociedades Democráticas de artesanos -organizaciones que congregaron a los trabajadores y pobres de gran parte de Colombia, especialmente a mediados del siglo-y el denominado golpe de José María Melo (17 de abril de 1854). Éste llevó al poder a un sector del ejército y a las Democráticas, quienes gobernaron hasta el mes de diciembre, cuando fueron derrotados en una guerra civil por una alianza entre liberales y conservadores.

Los artesanos en Colombia representaron un variopinto sector de trabajadores de las escasas actividades que podian considerarse industriales en aquel momento o que desempeñaban un oficio manual. A mediados del siglo XIX los artesanos se organizaron alrededor de Sociedades Democráticas, algunas de ellas por gremios y bajo la protección de un santo, empleando un lenguaje político avanzado, con claras referencias al primer socialismo europeo, con un plan de acción que incluia la lucha por la defensa de sus intereses, la oposición al libre cambio y, en algunos casos, la búsqueda de reformas sociales. La mayoría de ellas se guio por el reglamento de la Sociedad establecida en Bogotá en noviembre de 1847. Sus primeros pronunciamientos fueron una carta al congreso pidiendo la cancelación de las medidas que reducían los aranceles a la importación de productos manufacturados y el apoyo a la candidatura presidencial de José Hilario López, decidida por la mayoría en una asamblea. La Democrática inició sus actividades con 300 socios, pero gracias al apoyo que ofrecía a los artesanos, especialmente con diversos cursos de instrucción, defensa de sus actividades económicas y otros beneficios, a los dos años ya contaba con 1.500 miembros.

Sin embargo, los artesanos quedaron en medio de la confrontación

1. Este texto se elabora en el marco de actividades de año sabático gracias a la beca del Conacyt y la hospitalidad de la Goethe Universität de Frankfurt am Main, en particular la del profesor Roland Spiller. El autor agradece a los evaluadores anónimos y a los editores de la revista sus atinadas recomendaciones y espera haber respondido satisfactoriamente a la mayoría de ellas. 
entre liberales y conservadores que luchaban por el control del Estado y la implementación de su particular visión sobre el orden social, de alli que se buscó su incorporación a la lucha política, especialmente durante las guerras civiles que se sucedieron a lo largo del siglo. El sector radical del liberalismo -los denominados gólgotas- contribuyó a la circulación de los nuevos conceptos, entre ellos los de socialismo y comunismo, pero generó una confrontación al plantear el librecambio, que fue visto como la razón de la ruina de los productores locales y por ello con el paso del tiempo se presentó una ruptura con los artesanos. Por su parte, los conservadores también animaron su organización, pero con la clara intención de alejarlos de ideas radicales y para movilizarlos en torno a la defensa de la religión, el Papa y lo que en aquel entonces se consideraba la moral católica.

La mayor parte de los historiadores coinciden en señalar que, por una parte, el socialismo fue invocado por un sector del liberalismo, el ala radical de los gólgotas, y que tal hecho expresaba una contradicción entre los intereses políticos y económicos de un sector de la clase dominante y la necesidad de organizar a los artesanos para que apoyaran sus reformas (Colmenares, 1997: 108). Para otros, se trataba del exceso de interés por copiar las modas europeas y unos pocos académicos señalan la importancia y la originalidad de estas ideas en el escenario colombiano.

Los ataques contra Melo se originaron en juicios políticos del siglo XIX que consideraron que éste se impuso por un "golpe" o una "dictadura". En el siglo XX una valoración igualmente polémica fue la de Luis Ospina Vásquez, uno de los más importantes historiadores colombianos, quien criticó la experiencia del gobierno de Melo y de los artesanos de 1854. De igual forma los balances sobre la guerra civil de 1854, cuya bibliografia aún es escasa, también limitan el alcance del proyecto de Melo (Uribe de Hincapié y López Lopera, 2010: 355).

La visión apologética, que resalta la toma del poder por parte de sectores no hegemónicos por primera y única vez en la historia de Colombia, la exponen Gustavo Vargas Martinez (1972) y Carmen Escobar Rodríguez (1990). Los dos autores utilizan casi los mismos términos para referirse a los sucesos acaecidos entre abril y diciembre de 1854: de acuerdo a la segunda, fue "un acontecimiento histórico sin precedentes en la historia nacional del país. La primera revolución política eminentemente popular cuya dirección y hegemonía estaba en manos de la clase de los artesanos, de los militares y de la intelectualidad democrática pequeño burguesa" (Escobar Rodríguez, 1990: 268).

Por nuestra parte, creemos que la circulación de los conceptos de comunismo y socialismo en la Colombia del siglo XIX fue un proceso que estuvo ligado al impacto de las movilizaciones sociales que llevaron a la 
crisis al orden colonial, a la naturaleza del debate político entre liberales y conservadores, a los complejos vínculos con una tendencia planetaria $\mathrm{y}$, finalmente, a las características propias de los artesanos y a la forma que adquirió la defensa de sus intereses. Debido a la amplitud del tema únicamente haremos una mención muy rápida a los elementos señalados para centrarnos en el estudio de la circulación de los conceptos, pero siempre teniendo en cuenta que no fue resultado de una copia promovida por una adopción ingenua de un orden epistemológico occidental, eurocentrista y racista; ni por la "influencia" de la revolución de 1848; ni tampoco el resultado de una moda intelectual de los señoritos blancos e ilustrados de la ciudad letrada que luego fue impuesta a los artesanos. ${ }^{2}$ Por el contrario, se trata de un largo camino recorrido por los sectores populares de las grandes ciudades colombianas que "tradujeron"-leyeron desde sus circunstancias-a algunos escritores europeos y latinoamericanos y que dejaron en periódicos, memorias y diversos escritos y acciones políticas, que fueron comentadas por miembros de los partidos tradicionales, su particular manera de emplear estas nociones. De igual forma, el uso de los conceptos expresa las complejas alianzas entre elites y subalternos en el siglo XIX.

\section{Origen de los conceptos de comunismo y socialismo}

El surgimiento de los conceptos de comunismo y socialismo en Europa tiene una larga tradición que reúne cuatro tipos de experiencias de utopía social: la de las tradiciones religiosas ligadas a imágenes igualitarias del cristianismo, de alli el énfasis en una nueva moral que formularon los primeros socialistas; la de la literatura de utopía, muy popular en el siglo XVIII; la de las luchas sociales de artesanos y diverso tipo de trabajadores en el siglo XVIII y comienzos del XIX; y la de los teóricos que promovieron críticas a las extremas condiciones de los trabajadores, se opusieron a la burguesía y promovieron la necesidad de un nuevo orden social.

Para finales del siglo XVIII ya se encontraba activo François Babeuf

2. El debate alrededor del eurocentrismo nos parece útil desde el punto de vista teórico, pero de escasa utilidad para América Latina. En general, creemos que en el terreno de las ideas en nuestro continente no ha existido copia o sometimiento a epistemes occidentales. Por el contrario, encontramos una fuerte reelaboración de los conceptos, ideas, autores y libros; hubo aportes significativos al arte, la cultura y la ciencia; y ha sido permanente la estrecha colaboración con los intelectuales europeos y estadounidenses. Por ello, el punto de vista de los decoloniales de reivindicar el lugar de enunciación nos parece absurdo, especialmente cuando consideramos los aportes de la historia del libro, la historia conceptual o el funcionamiento de las redes intelectuales. 
y su grupo Los Iguales (1795-1796), considerado el primer partido comunista activo (Cordillot, 2014: 40 y ss). Al iniciarse el siglo XIX comenzaron a elaborarse planteamientos de los pioneros del socialismo, quienes reflexionaban sobre la naturaleza humana y a la vez proponían un plan de acción, un programa de transformación de la sociedad. Los estudiosos sobre el primer socialismo coinciden en señalar, como lo sostiene Michel Cordillot, que comunismo se entendía como "comunidad de bienes" y socialismo se concibió como contrario al individualismo o egoísmo, aunque era indiferente a la forma que adoptara el gobierno (2014: 40). Las formulaciones con cierto grado de elaboración del concepto de socialismo se produjeron alrededor de 1827 en Inglaterra por parte de quienes seguian las propuestas de Robert Owen, quien lo usó de manera clara en $1830 .{ }^{3}$ Este personaje, rico propietario de una industria textil, se preocupó por mejorar las condiciones de los trabajadores de su fábrica y por crear experimentos sociales en Estados Unidos, donde dio origen a una comuna para aplicar sus ideas, e incluso pensó una tentativa similar para México. Fue precisamente a partir de estas dos experiencias que comenzó a emplearse la noción de socialismo, que ganó gran popularidad dentro de los reformadores sociales de su época.

Posteriormente, con el surgimiento de la Liga de los Proscritos (1834), exiliados que buscaban una transformación de la situación social en Alemania, se dio un paso importante en la organización de los más radicales, proceso consolidado con la formación de la Liga de los Justos (1836), quienes se orientaban por el lema "Todos los hombres son hermanos". Sin embargo, lo más importante es que dos de sus activistas, Karl Schapper y Wilhelm Weitling, comenzaron a darle un matiz socialista y comunista a la Liga, planteando en 1838 que el protagonista de la transformación social debía ser la clase obrera. Tras una insurrección fallida en mayo de 1839, Schapper, Joseph Moll y Heinrich Bauer se establecieron en Londres y crearon la Sociedad Comunista de Formación Obrera, la cual publicó un manifiesto en un periódico de Hamburgo donde se aprecia una depuración de los conceptos (Bravo, 1976: 308). Por su parte, Marx y Engels comenzaron en los años 1840 una reelaboración de los presupuestos teóricos de los primeros socialistas y luego fundaron en 1846 el denominado Comité Comunista de

3. El empleo de la noción "socialismo utópico" para caracterizar las elaboraciones de las primeras décadas del siglo XIX se origina en el Anti-Dühring de Engels. Los críticos posteriores al utilizar la expresión "primitivo" tendieron a crear imágenes incorrectas sobre las limitaciones de pensadores como Saint-Simon, Charles Fourier y Robert Owen (Stedman Jones, 1984: 199 y ss). Las polémicas se mantienen hasta hoy día especialmente porque algunos historiadores comienzan la historia del socialismo en 1871 o porque no perciben la existencia de una corriente claramente diferenciada de socialismo en las primeras décadas del siglo XIX (Pilbeam, 2000). 
Correspondencia, con el cual iniciaron acercamientos a la Liga. En el congreso de 1847, la Liga encargó a Marx y a Engels la redacción de un programa, que finalmente adoptó el nombre de Manifiesto del Partido Comunista y se publicó el 21 de febrero de 1848. Además, se adoptó el nombre de Liga Comunista y la consigna: "Proletarios de todos los países uníos!". De manera que cuando Marx y Engels publican el Manifiesto los conceptos adquieren su configuración no solamente más elaborada sino la de uso corriente hoy dia (Droz, 1984: 607-608).

\section{Los artesanos y las ideas radicales en el siglo XIX}

Diversos historiadores han estudiado la gran capacidad de los subalternos para dotarse de liderazgos, organizaciones y teorías. George Rudé (1971), por ejemplo, sostuvo que puede hablarse de dos tipos de ideología en un movimiento popular: la inherente y la derivada. La primera es aquella elaborada por los propios sectores populares, mientras que la derivada es la que adoptan en su permanente contacto con las elites. Por supuesto, no se trata de dos construcciones contrapuestas, sino que se encuentran en permanente y mutua trasformación y reelaboración. Otros campos de saber, como la historia del libro, la historia de la lectura o la historia de la cultura popular, apuntan a una dirección similar: la precariedad en la que viven los subalternos o su analfabetismo no es impedimento para acceder al mundo de las ideas. De manera que descartamos cualquier consideración sobre la incapacidad o imposibilidad de los artesanos latinoamericanos del siglo XIX para acceder por su propia cuenta a las doctrinas radicales. Lo importante a nuestro juicio es analizar la forma específica que adquirió la traducción -circulación, apropiación y transformación- de los conceptos de socialismo y comunismo en la cultura popular colombiana del siglo XIX y estudiar los acontecimientos politicos que la hicieron posible.

Desde el siglo XVIII, y especialmente durante la independencia, existió una estrecha relación de los intelectuales con ideas radicales que circulaban en Europa y con las nuevas formas de sociabilidad, las empresas científicas, los viajes y las sociedades masónicas. La mayor parte de los líderes de la independencia fueron masones y en particular los más inclinados a romper las relaciones de dependencia con España se mostraron partidarios de asumir las tradiciones radicales de Inglaterra, Francia y Estados Unidos. No obstante, no se trató de una aplicación mecánica o copia de dichas ideas; por el contrario, pensamos que existió una importante reelaboración del lenguaje político. Lo importante para nuestra explicación es que la mayoria de quienes participaron en la formación de las Sociedades Democráticas, en la difusión de ideas radicales y en el levantamiento del 17 de abril de 1854, que para algunos puede 
ser catalogado como "socialista", habian tomado parte de una manera u otra en las luchas que dieron lugar a la independencia. Por ello fueron frecuentes los usos de pensadores socialistas y comunistas, pues toda esa generación estaba familiarizada con la idea de "revolución".

Por otra parte, hay que considerar que la formación de sociedades de artesanos comenzó en la década de 1820 y fue impulsada por el general Francisco de Paula Santander, encargado de la República de Colombia ante la ausencia de Simón Bolivar, en su afán de crear una nueva base política. De manera que también es necesario corregir el equívoco de los historiadores que señalan que este tipo de organizaciones irrumpieron a finales de los años 40. Creemos que es mejor hablar de ciclos, siendo el más prolifico el que va de 1847 a 1855, y que es al que se refieren la casi totalidad de los historiadores y quienes vivieron en aquel entonces y consignaron en memorias su opinión sobre el gobierno de José María Melo y los artesanos de 1854 .

En el siglo XIX existieron varios conceptos de uso frecuente con los cuales se quiso englobar a un variopinto conjunto de habitantes de la Nueva Granada. ${ }^{4}$ Inicialmente se empleó la noción de "pueblo" para referirse a los sectores que carecían de instrucción, recursos económicos y tenían derechos civiles limitados. Alrededor de la participación del pueblo en politica existieron dos enfoques: los que consideraban que era consecuencia de la manipulación de las pasiones y aquellos que pensaban que era el resultado de la labor de ilustración de las elites. De manera que, en cualquiera de los dos casos, se concebía al pueblo como un infante o carente de voluntad e instrucción. Posteriormente, y ya bajo la incorporación de noticias sobre la experiencia francesa, la noción de pueblo se sustituyó por la de ciudadano, pues a la hora de explicar el factor de cohesión de las sociedades las elites se encontraron ante la disyuntiva: ciudadanía o religión. Por ello, el debate fue alrededor de las libertades públicas (libertad de prensa, propiedad, amplios derechos civiles, etc.) y la moral.

Cuando comenzaron a circular, los conceptos de socialismo y comunismo se incorporaron a las polémicas alrededor de la definición del pueblo y la ciudadanía. Por ello podemos encontrar en un mismo artículo de prensa o comentario las posiciones de quienes concebían el socialismo como la posibilidad de acceso a la ciudadanía. Solamente a medida que se avanzó en la depuración de los conceptos se pudo establecer una clara distinción de términos.

4. Colombia tuvo los siguientes nombres a lo largo del siglo XIX, República de Colombia (unidad con Venezuela y Ecuador) (1819-1830); República de la Nueva Granada (1831-1858); Confederación Granadina (1858-1863); Estados Unidos de Colombia (1863-1886); República de Colombia (1886 en adelante). 


\section{Origen de los conceptos socialismo y comunismo en la Colombia del siglo XIX}

Desde mediados del siglo XIX se conocieron en América Latina corrientes de pensamiento que empleaban y difundian los conceptos de socialismo, comunismo e, incluso, marxismo, obviamente de una manera muy particular y sin el contenido que tienen hoy día. La mayor parte de estas corrientes se alimentaban de lo que genéricamente se ha denominado "utopías sociales" y que han tenido una larga tradición en el pensamiento y la literatura. ${ }^{5}$

Es necesario señalar que en el siglo XIX se presentaron una serie de circunstancias que privilegiaron la circulación de nuevos conceptos: existió desde la independencia un amplio uso de lenguaje político radicalizado. En segundo lugar, el ascenso de las Sociedades Democráticas y el golpe de José María Melo estimularon las posturas radicales en los artesanos colombianos. Finalmente, hay que mencionar que a lo largo del siglo XIX existió una amplia búsqueda de doctrinas y autores que representaran las vanguardias políticas y no fue ajena la circulación de ideas al mismo tiempo que se encontraban en boga en otros países. Ello explica que, en la Colombia del siglo XIX, también se conocieran los conceptos elaborados por los primeros socialistas.

La coyuntura de la historia de Colombia en la que usualmente se detienen los historiadores es la de mediados del siglo XIX, caracterizada por tres eventos muy importantes: el gobierno de José Hilario López (1849-1853), en el que se aplicaron las reformas liberales de medio siglo, como la libertad de los esclavos; la fundación de las Sociedades Democráticas de artesanos, agrupaciones que difundieron un mensaje de igualdad; y el ascenso al poder de José María Melo (7 de abril de 1854), el cual fue respaldado por los artesanos de Bogotá, quienes gobernaron hasta el 4 de diciembre con propuestas de reforma social. ${ }^{6}$

Melo fue un militar descendiente de indígenas pijaos, participó activamente en las actividades de la conformación de la República de Colombia y desde Venezuela luchó en 1835 por su restauración. Tras su

\footnotetext{
5. Algunos estudios parten de la consideración de que el marxismo se inició con la fundación de los PC y le brindan poca atención a los pensadores del siglo XIX; véase a manera de ejemplo Guadarrama González (1999). Una propuesta que rescata los primeros pasos del socialismo en Argentina en Tarcus (2016); para el caso de México, véase Illades (2008).

6. Para el conservatismo se trató de un "golpe militar" y una "dictadura". Un relato de los protagonistas de la guerra civil que se desató luego del ascenso de Melo al poder en Venancio Ortiz (1855). Véase además el folleto anónimo La revolución. Orijen, progresos, fines $i$ estado actual de la revolución democrática, que se prepara en esta ciudad, Bogotá, Imprenta F.T. Amaya, abril de 1858.
} 
derrota debió viajar a Inglaterra, donde continuó sus estudios militares, y se acercó a las ideas que impulsaban los reformistas sociales. En 1841 retornó a Ibagué (la actual capital del departamento del Tolima) y se involucró con los artesanos. Bajo el gobierno de José Hilario López fue nombrado general con la tarea de defender la reciente libertad de los esclavos (1851). ${ }^{7}$ Luego de asumir el gobierno provisional en abril de 1854 , y tras ser derrotado, tuvo que viajar a Centroamérica y después a México: alli defendió la causa de Benito Juárez en las Guerras de Reforma, por lo que fue fusilado en 1860 (Ortiz Vidales, 2002).

Las sociedades, católicas o democráticas, tuvieron un periodo de auge a finales de la década del 30. En mayo de 1838 Ignacio Morales fundó en Bogotá la Sociedad Católica y posteriormente, el 10 de julio, Lorenzo María Lleras y Juan Nepomuceno Vargas hicieron lo mismo con la Sociedad Democrática Republicana de Agricultores i Labradores Progresistas de la Provincia de Bogotá. En octubre de 1847 surgió la Sociedad de Artesanos, de carácter mutualista y pedagógico, que dos años más tarde se transformó en Democrática, y también la Sociedad de Bogotá. Se ha calculado que el número de asociados en sus mejores momentos fue de alrededor de 4.000 individuos, cuando la ciudad tenía 25.000 habitantes. En la década del 40 los ecos de la revolución de 1848 y los sucesos politicos nacionales fortalecieron a las Democráticas en todo el país. Para mediados de la década siguiente existió un nuevo auge de fundación de sociedades en gran parte del país: alrededor de 112 según la Gaceta Oficial, aunque las más fuertes se concentraron en Bogotá, pues había allí más artesanos y mayores recursos para crear periódicos y publicar hojas volantes.

Existe un debate historiográfico sobre el impacto de las ideas de los primeros socialistas en la Colombia de mediados de siglo. Desde hace varias décadas historiadores como Jaime Jaramillo Uribe hablaron de una "etapa romántica" en la cual la circulación de autores franceses fue fundamental, entre ellos Eugenio Sue, Víctor Hugo y especialmente Alphonse de Lamartine (Jaramillo Uribe, 1968: 21). La importancia de estos escritores fue señalada por José María Samper, testigo de excepción de los sucesos, quien resaltaba especialmente a Lamartine, cuando comentaba su encuentro en París con el escritor francés, a quien le habló de la importancia de sus ideas en el país y de la circulación de sus libros, especialmente Viaje a Oriente (1835) y la Historia de los Girondinos (1847).

7. José Hilario López (1798-1869) se vinculó al ejército libertador desde los 14 años y participó en las más importantes batallas de la guerra de independencia; asumió el cargo de presidente el 7 de marzo de 1849 gracias a la presión de los artesanos, por lo que el suceso fue bautizado por los conservadores como "la noche de los puñales"; y fue el artífice de las reformas liberales de medio siglo. 
José María Samper, quien inicialmente fue animador del socialismo y luego defensor del proyecto más retardatario del conservatismo, nos permite apreciar que a mediados del siglo XIX existía en Colombia un conocimiento de los autores que en Europa desarrollaban el conjunto de ideas que fueron bautizadas posteriormente como "primer socialismo", aunque en su caso, afirmó, las teorias no las había aprendido en Fourier, Saint Simon, Proudhon ni Blanc sino en la Biblia (Samper, 1858: introducción). ${ }^{8}$

Por su parte Rafael Núñez, quien más adelante fue presidente de Colombia, haciendo un balance de esta coyuntura resaltó el impacto de la revolución del 48 en Francia y la presencia de Lamartine y sostuvo, además, que en la Nueva Granada eran muy populares Louis Blanc y Pierre-Joseph Proudhon. Por ello concluyó que "de 1849 en adelante tuvimos un verdadero alud de utopías y paradojas francesas" (Nieto Arteta, 1962: 231).

Evidentemente, desde ese mismo momento se estableció en la oposición conservadora un rechazo al socialismo y al comunismo con un doble argumento: son ideas europeas que no son útiles en Colombia y éstas solo buscan la movilización de un pueblo ignorante en torno a proyectos de disolución de la nación y la religión. Por ello los políticos que vivieron en esa época y dejaron memorias, como José María Obando, argumentaron que no eran las mismas condiciones europeas las que prevalecían en la Nueva Granada, pues en el viejo continente se explotaba inmisericordemente a las masas obreras y en Colombia se podría prevenir el impacto negativo del capitalismo (Obando, 1853).

Las reflexiones históricas, aún en el siglo XX, estuvieron cargadas de prejuicios elitistas que reproducian juicios de valor sobre los artesanos elaborados en el siglo XIX. Lo particular es que tal postura ha sido sostenida por historiadores de reconocida trayectoria como Luis Eduardo Nieto Arteta, para quien los artesanos se caracterizaron por la "insignificancia de sus pretensiones" y por ser simplemente instrumento utilizados por los políticos (Ospina Vásquez, 1974: 225).

Los sectores más retardatarios de la sociedad rechazaron estos discursos igualitarios y vieron en los democráticos a lo más bajo de la sociedad: en una mezcla de elitismo y racismo comenzaron a emplear el término de "Guaches" para identificarlos. ${ }^{9}$ Fueron igualmente comunes los ataques contra las Democráticas señalando las limitaciones del

8. Fue tan importante esta influencia del cristianismo que el sector del Partido Liberal más radical fue denominado "gólgota" por su permanente referencia a Cristo en sus discursos.

9. Según el diccionario del RAE, la palabra se origina en el término quechua "huacha", que significa pobre. En la Colombia de siglo XIX quería decir, además, ruin y canalla. 
pueblo. En un documento del 23 de agosto de 1851 contra la Sociedad Democrática de San Gil (Departamento de Santander) se lee: "La democrática de aquí no se compone sino de una media docena de bribones degradados en la opinion, tramposos por oficio i fallidos por sus vicios; de hombres escandalosos como casados, entregados a la crápula, acribillados de deudas, i que quieren saldar cuentas i cubrir su relajacion gritando democracia".

De manera enfática, los críticos de la Democrática ampliaron sus juicios con los siguientes argumentos:

El espíritu de secta que la tumultuaria demagojia pretende establecer en todas partes, a fin de que los mas corrompidos i los mas inmorales sean los Señores de la Nacíon, unido al odio que naturalmente inspiran a los secuaces de esta escuela, los hombres o los pueblos que tienen independencia o alguna riqueza; debía producir su eco en esta provincia i lo ha producido en efecto Los Sanjileños han sido escojidos como víctimas, i cuando se vió que su union i su entereza podían preservarlos, se ocurrió al espediente de producir una escision entre sus hijos estableciendo la mas inicua, la mas infame i la mas injusta de las divisiones entre nosotros, a saber, una guerra de castas. Aquí ha tenido orijen en la Sociedad democrática, que para darle un aspecto político i para pretender hacerla prestijiosa se la ha apellidado "Obando". ${ }^{10}$

Lo interesante de esta respuesta a la creación de la Sociedad Democrática en San Gil es que empleó la noción de comunismo y, por otra parte, destacó el peligro que representaban los democráticos para dos hechos considerados sagrados: propiedad y mujeres. Señalaba el documento:

El objeto de la democrática es corromper al pueblo nuestro, tendiendo a establecer el comunismo de los bienes i la libertad ó el comunismo de las mujeres. ${ }^{11}$

\section{El uso de los conceptos de socialismo y comunismo}

Una de las primeras referencias a los conceptos apareció en 1849 en el periódico El Alacrán, que publicó un artículo titulado "Comunismo" donde se hacia una referencia directa al concepto y a sus implicacio-

10. A los autores de la publicación que contiene el programa de la Sociedad Democrática "Obando" de Sanjil. p. 3. Las cursivas son del original.

11. Ibídem. 
nes. Dada la importancia del texto nos atrevemos a citarlo a pesar de su extensión:

Nuestro enemigo es la clase rica, nuestros enemigos reales son los inicuos opresores, los endurecidos monopolistas, los agiotistas protervos. ¿Por qué esta guerra de los ricos contra nosotros? Porque ya han visto que hay quien tome la causa de los oprimidos, de los sacrificados, de los infelices, a cuyo número pertenecemos; porque son acusados por su conciencia de su iniquidad; porque saben que lo que tienen es una usurpación hecha a la clase proletaria y trabajadora, porque temen que se les arrebaten sus tesoros reunidos a fuerza de atroces exacciones y de diarias rapiñas, porque temen verse arrojados de sus opulentos palacios, derribados de sus ricos coches con que insultan la miseria de los que los han elevado allí con sus sudores y su sangre; porque ven que las mayorías pueden abrir los ojos y recobrar por la fuerza lo que se les arrancó por la astucia y la maldad; porque temen que los pueblos desengañados y exacerbados griten al fin como, deben hacerlo y lo harian un día no lejano: jabajo los de arriba!; porque saben que el comunismo será y no quieren que sea mientras ellos viven, infames egoístas. Sí, el comunismo será; ¿por qué no había, de serlo? ¿En qué apoyarán sus derechos los expoliadores del género humano? ¿Será por ventura en la justicia? ¡ Irrisión! Pero la palabra comunismo pertenece ya al dominio de las mayorias; la discusión está abierta; de la discusión brotará la verdad; las masas conocerán al fin que unos pocos hombres están gozando solos de los bienes ¡las dichas que el Supremo Creador puso en el mundo para todos! en las masas está la fuerza;

Temblad ¡oh! monstruos que se acerca él día.

Temblad tiranos de lá especie humana, ya la coyunda que el error ponía rota en pedazos volará mañana; ¿Qué son vuestros derechos? ¡Ironía! Inventor torpe de ambición insana; el eco de ¡venganza! hondo, profundo resuena por los ámbitos del mundo. ${ }^{12}$

12. El periódico fue fundado por Joaquín Pablo Posada y Germán Gutiérrez de Piñerez; su primer número se publicó el 28 de enero de 1849 y el último el 22 de febrero del mismo año. Durante su corta existencia generó una gran polémica por su lenguaje y sus ideas, fue ampliamente recibido por los artesanos de Bogotá, pero igualmente perseguido por los poderosos de la ciudad y generó un duelo a cuchillo entre uno 
El 29 de enero de 1852 se publicó en Bogotá un periódico titulado El Socialista. El amigo del pueblo, en apoyo al caudillo militar José María Obando y al gobierno de López. Lo interesante es que en ese momento se empleó nuevamente el concepto de "comunismo":

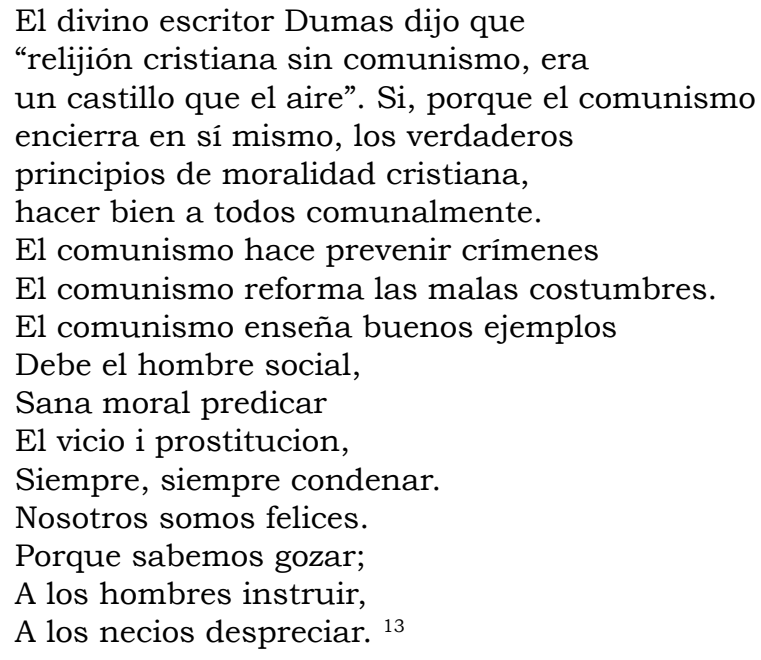

En el mismo año circuló un trabajo firmado por Carlos Mazade, fechado en París el 15 de mayo de 1852 aunque impreso en Bogotá, en el que se analizaban las posibilidades del socialismo para los países de América del Sur. Lo particular, además de anticipar que Panamá terminaría siendo parte de Estados Unidos, es que señaló las limitaciones del socialismo dado el escaso control del territorio existente en la Nueva Granada (Colombia) y el tamaño de su población, además de otros factores. No obstante, identificaba todo tipo de excesos del pueblo radicalizado que protestaba en todo el país con las acciones de las Sociedades Democráticas y con el socialismo, con la clara intención de

de los ofendidos y Posada y el encarcelamiento de los editores, aunque luego fueron indultados por el recién elegido presidente López, quien anuló los cargos por delitos de imprenta. La mayoría de los autores que escriben sus memorias sobre el período resaltan estos hechos (Cordovez Moure, 2006: 890-897; Borda, 1974: 63 y ss). Los editores fueron miembros de la logia Estrella del Tequendama, encarcelados por el delito de difamación, y Posada fue el redactor de El 17 de abril, periódico oficial del régimen de Melo. Un análisis del juicio a los editores de El Alacrán en Ruiz (2016: 279-305).

13. El Socialista. El amigo del pueblo, 29 de enero de 1852. Loaiza Cano (2014) nos brinda otros ejemplos de circulación del concepto socialismo y una completa imagen de la relación entre los liberales y los artesanos miembros de la Sociedades Democráticas. 
desprestigiarlo (Mazade, 1852). ${ }^{14}$ Esta postura se empleó para justificar la violencia que se desató contra las democráticas y los artesanos que respaldaron a Melo en Bogotá. En efecto, liberales y conservadores se aliaron militarmente y desataron una cruenta represión para aplastar al pueblo radicalizado, por lo que muchos fueron desterrados a calurosas cárceles en el Caribe.

En otro escrito elaborado para hacer un balance sobre el avance del socialismo en América del Sur se desarrolló una feroz crítica al proyecto de López y al socialismo y una defensa del catolicismo. Nos permitimos citar en extenso el documento para tener los elementos necesarios para entender qué era lo que se temía del socialismo en aquel entonces. El autor del documento sostenía:

Creemos que la cuestion social que ajita actualmente la América i la Europa, puede enunciarse en estos breves términos: ¿Son los principios de la relijion cristiana los mejor calculados para fundar sobre ellos la sociedad? Los que resuelven esta cuestion negativamente se llaman socialistas. Esta secta tiene dos escuelas: la una pretende destruir todo lo que existe, sin proponer cosa alguna en su lugar, para que del desórden sumo, salga el bien, como el mundo salió, en concepto de ellos, del caos -es decir, por "casualidad"-; la otra pretende, que desaparezcan la familia, la relijion cristiana i la propiedad, para sustituir al matrimonio la promiscuidad de las mujeres; a los cuidados paternos, los de un poder comun que crie, cuide i eduque los niños; a la propiedad, la administracion de los bienes por un poder tambien comun, que reparta entre los hombres lo necesario para satisfacer sus necesidades; i que no permita a nadie gozar de lo superfluo, mientras todos no tengan lo necesario. Hai, pues, dos sectas de socialistas: 1. Socialistas destructores. 2. Socialistas visionarios.

El centro de estas dos sectas está en Francia, pero sus ajentes andan por todo el mundo, i en todas partes aparecen asumiendo diferentes formas, segun que conviene al progreso de sus doctrinas. La maña, la astucia, la hipocresía, la violencia, la adulacion, la calumnia, la incredulidad, hasta la pre-

14. Este folleto generó una polémica en la Nueva Granada, anota Restrepo en su Diario: "Se ha publicado en París un folleto titulado El Socialismo en América del Sur, su autor, Carlos Mazade, da un fuerte ataque al gobierno de López y socios y les hace cargos harto graves. Les hirió mucho este papel que contestara en la discusión el vicepresidente Obaldía, con la palabrería que acostumbra pero sin solidez. Probablemente aquel escrito y otros varios atribuyendo el socialismo al gobierno de López, ha obligado a los miembros que redactaron la discusión a repetir cada semana un artículo en que niegan que sean socialistas y comunistas" (Restrepo, 1954, IV: 257) 
dicacion del cristianismo, todo les sirve, de todo echan mano. Los socialistas cuentan ademas con muchos instrumentos, que estan trabajando para ellos, i no lo saben, como el buen hombre de Moliére, que al cabo de muchos años de estar escribiendo, no sabia que estaba escribiendo prosa.

Ambas sectas socialistas están de acuerdo en que la familia i la propiedad son inconvenientes sociales que deben removerse; i como precisa e indispensable consecuencia, sostienen que el cristianismo no consulta las necesidades, ni resuelve los problemas sociales (Eldropeito, 1852: 6 y 7).

A pesar de que Colombia era un país con limitado poder económico, a mediados del siglo XIX visitaron el país Mijail Bakunin y Élisée Reclus, importantes difusores del anarquismo. El primero de ellos estuvo de paso en Panamá, territorio que formó parte de Colombia hasta 1903. El segundo arribó en 1855 y permaneció dos años realizando una expedición científica de la cual surgió el libro Viaje a la Sierra Nevada de Santa Marta, publicado en 1861 en París (Reclus, 1869).

Sin embargo, la mayor presencia de un pensador anarquista fue la de Proudhon, autor que fue frecuentemente citado en la prensa de mediados de siglo, especialmente en el periódico El Neogranadino, en el que escribieron el radical liberal Manuel Murillo Toro y el joven conservador Manuel María Madiedo, conocido por fundir ideas católicas y socialistas. Son muchos los artículos que se pueden comentar y que permiten apreciar el rastro de los primeros socialistas europeos, pues permanentemente se escribe por ejemplo contra los monopolios. ${ }^{15}$ Estas ideas de Murillo Toro, en calidad de Secretario de Hacienda del gobierno de José Hilario López, las llevó a un proyecto de reforma que fue aprobado por el congreso, aunque objetado por el presidente. En su artículo cuarto señalaba: "ninguno podrá hacerse en adelante dueño de una extensión de tierra de la perteneciente al Estado mayor de mil fanegadas". No obstante, a juicio de Germán Colmenares la oposición de Murillo Toro a los monopolios escondía la defensa de la propiedad de la tierra, pues para él la explotación capitalista era confundida con la que ejercian los terratenientes. De igual forma, su oposición a los monopolios, especialmente del tabaco, tenía una mezcla de defensa de los pequeños propietarios y su rechazo al laissez faire era una puerta abierta a la apropiación, por lo cual se mostró partidario de la intervención estatal (Colmenares, 1997: 109-110).

15. En el primer número del periódico El Neogranadino, donde se señalan su ánimo crítico y de buscar la imparcialidad ante los partidos politicos, Madiedo escribe, citando previamente a Comte, el artículo "Monopolio del tabaco" (4 de agosto de 1848); más adelante se puede leer "Abajo los monopolios" (2 de abril de 1852). 


\section{Comentario final}

Para responder a la pregunta de por qué los artesanos colombianos de mediados del siglo XIX conocieron y emplearon los conceptos de socialismo y comunismo, es necesario comprender varios fenómenos de larga, media y corta duración. El primero de ellos es una tradición de lucha de los subalternos antes, durante y luego de la independencia. Pensar que las revoluciones de esta época fueron resultado de la acción política de las elites criollas es un error, tanto como suponer que se trató de movimientos que simplemente reflejaban lo que sucedió en las cortes de Cádiz y el ascenso de ideas liberales en España. Por el contrario, hay que señalar dos hechos capitales: el que los sectores populares estuvieron en capacidad de crear sus propias nociones de orden político y que la independencia expresó la existencia de una alianza entre elites y subalternos. Con lo primero queremos decir que es necesario considerar los movimientos de masas, especialmente de 1781 en adelante, como una gran escuela en la que se formaron campesinos y artesanos. ${ }^{16}$ Creemos que sin observar los resultados de estas protestas es imposible apreciar que estas generaron liderazgos, dotaron a los subalternos de herramientas interpretativas, formas de sociabilidad modernas, etc.

Además, existió un movimiento republicano, mestizo y negro, en los inicios de la independencia de la Nueva Granada, el cual tuvo como centro político a Cartagena de Indias. Alli se dieron nuevamente dos hechos significativos: las posiciones más radicales que reclamaban la independencia y la alianza de clases.

Luego de la guerra civil de 1854 los artesanos fueron debilitados política y organizativamente y, además, sufrieron el embate del catolicismo que acentuó su pretensión de organizarlos y controlarlos en sociedades católicas. Sin embargo, los ecos de la coyuntura de mediados de siglo se volvieron a escuchar en la década de los 70 a propósito del denominado "Motín del Pan", cuando a raíz de un alza inusitada en los precios del alimento se desató una fuerte protesta contra las panaderías de la ciudad y se obligó a los tenderos a retornar a los precios originales. Lo particular fue que las consignas agitadas durante la protesta tuvieron una clara mención a la revolución francesa, pues se lanzaron vivas a Robespierre, Danton y otros líderes.

16. La historiografia de la independencia tiene un largo debate sobre la participación de los subalternos. Sin entrar en detalle diriamos que en algunos historiadores hay un reconocimiento de un período de auge de las luchas sociales, aunque la mayor parte de los autores limitan sus alcances políticos, en particular su papel en la independencia y sus acciones las conciben como reacciones conservadoras a las reformas borbónicas. Estudios clásicos son Phelan (2009), McFarlane (1984) y, para México, Van Young (2006). 
Con el paso del tiempo las referencias a los conceptos de socialismo y comunismo comenzaron a presentarse con el contenido que hoy le asignamos. Varias razones explican esta circunstancia: el conocimiento de los sucesos de la Comuna de París; la censura de la Iglesia católica que desde la publicación del Syllabus y otros documentos condenaron al socialismo y con ello permitió, aunque falseando los hechos, la circulación del concepto; la acción de organizaciones anarquistas y socialistas, que vivieron una etapa de auge en América Latina; y una mayor presencia de redes intelectuales y medios de comunicación, con lo cual las noticias y libros circularon ampliamente.

El inicio de un período denominado "hegemonía conservadora" (18801930) fortaleció aún más las dinámicas de control de la Iglesia católica y de las elites más retardatarias de la ciudad y el campo. En la constitución de 1886 se impidieron las sociedades secretas, especialmente la masonería. Además, a diferentes niveles se impuso la censura, se estableció un índice de lecturas prohibidas y la necesidad de dispensa eclesiástica para leer periódicos liberales y se consideró un pecado a esta corriente política. En su afán por cuestionar las costumbres de los pobres de la ciudad, la prensa católica calificó con los peores términos las prácticas cotidianas de los subalternos, especialmente de aseo. Esto fue catalogado como una afrenta por los sectores pobres de la ciudad, quienes en 1893 generaron violentas protestas, que luego se articularon con un intento de guerra civil liderada por los liberales para detener a los conservadores (Aguilera, 1997).

Los sectores más retardatarios de la época consagraron una idea: el socialismo se justificaba en Europa por el impacto del capitalismo y por la creación de una masa de menesterosos, pero en Colombia estaba todo por hacer y era posible que los relativamente pocos pobres encontraran oportunidades en el trabajo. La mayor parte de los historiadores coinciden en señalar que el socialismo era expresión de un sector del liberalismo, del ala radical de los gólgotas. Para otros, se trata del exceso de las modas intelectuales que llevaron a copiar las ideas producidas en Europa. Ambas posiciones, a nuestro juicio, son herederas de la visión conservadora del siglo XIX que despreció el proyecto de gobierno de Melo y la acción de las Democráticas.

Creemos que, en la Colombia del siglo XIX, dada la naturaleza de la confrontación entre liberales y conservadores y la debilidad numérica de los artesanos y otra serie de limitantes, el encuentro con los conceptos de socialismo y comunismo se manifestó en una pluralidad de alternativas. Existieron en las elites liberales socialistas circunstanciales, como José Maria Samper; artesanos influenciados por una gran variedad de representaciones sobre la religión y la utopía social; y, finalmente, un grupo decididamente inclinado a la aplicación de las nuevas ideas, aunque 
evidentemente minoritario. Este pequeño grupo fue el que mantuvo, a pesar de las circunstancias, la denominación de socialismo y comunismo y siguió ahondando en la lectura del pensamiento crítico. Los herederos de este último sector, a finales del siglo XIX y especialmente a comienzos del siglo pasado, dieron origen a organizaciones politicas claramente socialistas y comunistas y, por supuesto, a corrientes anarquistas, y tuvieron la capacidad de emplear los conceptos de acuerdo a los problemas locales que enfrentaban los subalternos. Es decir, los enriquecieron con nuevos contenidos y los usaron creativamente y de acuerdo a las demandas de la coyuntura histórica y a las necesidades de la movilización social.

\section{Referencias}

Aguilera Peña, Mario (1997), Insurgencia urbana en Bogotá. Motín conspiración y guerra civil, 1893-1895, Bogotá: Colcultura.

Borda, Francisco de Paula (1974), Conversaciones con mis hijos, Bogotá: Biblioteca Banco Popular, vol. 65, tomo I, pp. 63 y ss.

Bravo, Gian Mario (1976), Historia del socialismo, 1789-1848. El pensamiento socialista antes de Marx, Barcelona: Ariel.

Colmenares, Germán (1997), Partidos politicos y clases sociales [1968], Bogotá: Universidad del Valle-Colciencias-Tercer Mundo.

Cordillot, Michel (2014), "Socialismo y comunismo en Francia, 1830-1848", en Carlos Illades y Andrey Schelchkov (coords.), Mundos posibles. El primer socialismo en Europa y América Latina, México: El Colegio de México-Universidad Autónoma Metropolitana-Cuajimalpa, pp. 37 y ss.

Cordovez Moure, José Maria (2006), Reminiscencias de Santafé y Bogotá, Bogotá: Fundación Editorial Epígrafe.

Droz, Jacques (1984), "El socialismo alemán del Vormärz", en Jacques Droz (dir.), Historia general del socialismo. De los origenes a 1875, Barcelona: Destino.

Eldropeito (1852), Las republicas hispanoamericanas y el socialismo, Bogotá: reimpreso por Nicolás Gómez, 26 de enero de 1852.

Escobar Rodríguez, Carmen (1990), La revolución liberal y la protesta del artesanado, Bogotá: Fondo Editorial Suramérica.

Guadarrama González, Pablo (1999), "Bosquejo histórico del marxismo en América Latina", en Despojado de todo fetiche. Autenticidad del pensamiento marxista en América Latina, Bogotá: Universidad INCCA de Colombia, Universidad Central de Las Villas, capitulo 1, pp. 1-72.

Illades, Carlos (2008), Las otras ideas: estudios sobre el primer socialismo en México, 1850-1935, México: Era.

Jaramillo Uribe, Jaime (1968), "Tres etapas de la historia intelectual de Colombia", Revista de la Universidad Nacional (1944-1992), Bogotá, $1968, \mathrm{n}^{\circ} 1$, pp. 5-26. 
Loaiza Cano, Gilberto (2014), "Del débil utopismo de las élites a la formación de una cultura política popular en Colombia", en Carlos Illades y Andrey Schelchkov (coords.), Mundos posibles. El primer socialismo en Europa y América Latina, México: El Colegio de México-Universidad Autónoma Metropolitana-Cuajimalpa, pp. 189 y ss.

Mazade, Carlos (1852), El socialismo en la América del Sur, Bogotá: Espinosa.

McFarlane, Anthony (1984), "Civil disorders and popular protests in late colonial New Granada", en Hispanic American Historical Review, 64 (1), 1984, pp. 19-54.

Nieto Arteta, Luis Eduardo (1962), Economía y cultura en la historia de Colombia, Bogotá: Tercer Mundo.

Obando, José María (1853), "Alocución a los granadinos, del $1^{\circ}$ de abril de $1853 "$ ".

Ortiz, Venancio (1855), Historia de la revolución del 17 de abril de 1854, Bogotá: Francisco Torres Amaya.

Ortiz Vidales, Darío (2002), José María Melo: la razón de un rebelde [1980], Ibagué: Producciones Géminis.

Ospina Vásquez, Luis (1974), Industria y protección en Colombia, 1810-1930, Medellin: La Oveja Negra.

Phelan, John L. (2009), El pueblo y el Rey. La revolución comunera en Colombia, 1781, Bogotá: Universidad del Rosario.

Pilbeam, Pamela (2000), French Socialists Before Marx, Durham: Acumen.

Reclus, Élisée (1869), Viaje a la Sierra Nevada de Santa Marta, Bogotá: Foción Mantilla.

Restrepo, José Manuel (1954), Diario politico y militar: memorias sobre los sucesos importantes de la época para servir a la Historia de la Revolución de Colombia y de la Nueva Granada, desde 1819 en adelante, Bogotá: Imprenta Nacional, 4 tomos.

Rudé, George (1971), La multitud en la historia. Los disturbios populares en Francia e Inglaterra 1730-1848, Madrid: Siglo XXI.

Ruiz, Paola (2016), "La libertad de imprenta en la Nueva Granada: los juicios contra El Alacrán a mediados del siglo XIX", en Anuario Colombiano de Historia Social y de la Cultura, Universidad Nacional de Colombia, Bogotá, vol. 43, n², pp. 279-305.

Samper, José María (1858), Apuntamientos para la historia social i politica de la Nueva Granada 1810, i especialmente de la administración del 7 de Marzo, Bogotá: Imprenta del Neogranadino.

Stedman Jones, Gareth (1984), "Reconsideración del socialismo utópico", en Raphael Samuel (ed.), Historia popular y teoría socialista, Barcelona: Crítica, pp. 199 y ss.

Tarcus, Horacio (2016), El socialismo romántico en el Río de La Plata (18371852), Buenos Aires: Fondo de Cultura Económica.

Uribe de Hincapié, María Teresa y Liliana María López Lopera (2010), Las palabras de la guerra: metáforas, narraciones y lenguajes politicos. Un 
estudio sobre las memorias de las Guerras Civiles en Colombia, Medellin: La Carreta.

Van Young, Eric (2006), La otra rebelión. Lucha por la independencia de México, 1810-1821, México: Fondo de Cultura Económica.

Vargas Martínez, Gustavo (1972), Colombia 1854: Los artesanos y el socialismo, Bogotá: La Oveja Negra. 